\title{
A Review of an Intelligent System for Detecetion of Potholes and Humps
}

\author{
Swati K. Mohod', Dinesh B. Bhoyar' ${ }^{2}$, S.S. Khade ${ }^{3}$ and K. D. Kulat ${ }^{4}$ \\ ${ }^{1}$ Assistant Professor, Department of EL, Yeshwantrao Chavan \\ College of Engineering, Nagpur, Maharashtra, India \\ ${ }^{2}$ Assistant Professor, Department of ETC, Yeshwantrao Chavan \\ College of Engineering, Nagpur, Maharashtra, India \\ ${ }^{3}$ Assistant Professor, Department of ETC, Yeshwantrao Chavan \\ College of Engineering, Nagpur, Maharashtra, India \\ ${ }^{4}$ Professor, Department of ECE, Visvesvaraya National Institute \\ of Technology, Nagpur, Maharashtra, India
}

\section{ABSTRACT}

Roads are the major means of transportation and it supports the nation's economy only if they are well maintained. It is necessary to identify homes and potholes so the accidents can be avoided and the damage caused to the vehicle is less. It also contributes in saving fuel. Here is a simple and effective solution regarding the problem of accidents by detection of potholes and humps and help drivers. Detection of potholes will be done by image processing technique and humps would be detected by ultrasonic sensor. Raspberry Pi is the controlling device. Wi-Fi will be used to acquire geographical position of potholes and will be send to the authority to take appropriate measures

KEY WORDS: RASPBERRY PI, WI-FI, ULTRASONIC SENSOR, GPS RECEIVER, GSM SIM 900, CAMERA.

\section{INTRODUCTION}

Roads connect numerous cities in Bharat and villages with the cities. They're a vital mode of transport in Bharat. Bharat incorporates a network of over 5,897,671 kilometer of roads. This is often the second largest road network within the world. Bharat has close to 4.87 kilometer of roads per 1,000 people. India's road network carries over $65 \%$ of its freight and regarding $85 \%$ of rider traffic. It contributed $4.7 \%$ towards India's domestic product. In

\section{ARTICLE INFORMATION}

*Corresponding Author: kdkulat@ece.vnit.ac.in

Received 17th Oct 2020 Accepted after revision 24th Dec 2020

Print ISSN: 0974-6455 Online ISSN: 2321-4007 CODEN: BBRCBA

Thomson Reuters ISI Web of Science Clarivate Analytics USA and Crossref Indexed Journal

\section{1) Clarivate $\begin{gathered}\text { Analytics } \\ \text { rossef }\end{gathered}$}

NAAS Journal Score 2020 (4.31)

A Society of Science and Nature Publication,

Bhopal India 2020. All rights reserved.

Online Contents Available at: http//www.bbrc.in/

Doi: $h t t p: / / d x$.doi.org/10.21786/bbrc/13.14/100 step with ministry of Road Transport and Highways as of March 2019 Bharat had regarding 1,42,216 kilometer of national highways and expressways and another 1,76,166 kilometer of state highways. Major comes being enforced beneath the National Highways Development Project a government initiative. However, on the opposite hand, it's sealed the manner increasing range of RTA (road traffic accident).As per the survey of WHO 1.35 million people died every year due to road accidents. Due to road traffic crashes their gross Domestic Product. Our aim is to develop an intelligent system for detecting the potholes and humps of the road. The same will be inform to the municipal commissioner for taking some safety measures [2]. The road accident due to potholes is shown in figure- 1 .

2. Related work: The Raspberry Pi as shown in figure-2 is additionally a series of little single-board computers developed at intervals the UK by the Raspberry Pi Foundation. The SIM900 is additionally an entire

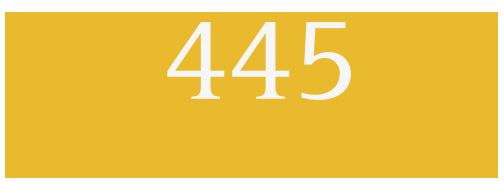


Quad-band GSM/GPRS answer throughout a SMT module which may be embedded at intervals the patron applications that have Associate in Nursing industrystandard interface; the SIM900 delivers GSM/GPRS $850 / 900 / 1800 / 1900 \mathrm{MHz}$ performance for voice, SMS, Data, and Fax throughout a tiny low kind issue and with low power consumption. With a tiny low configuration of $24 \mathrm{~mm} \times 24 \mathrm{~mm} \times$ three metric quantity, SIM900 will match the majority the house wishes in your M2M application, considerably for slender and compact.[6] Ultrasonic sensors generate the ultrasonic waves for measuring the distance between the vehicle and the object. Ultrasonic Sensors consist of two transducers for transmitting and receiving purpose. [4]

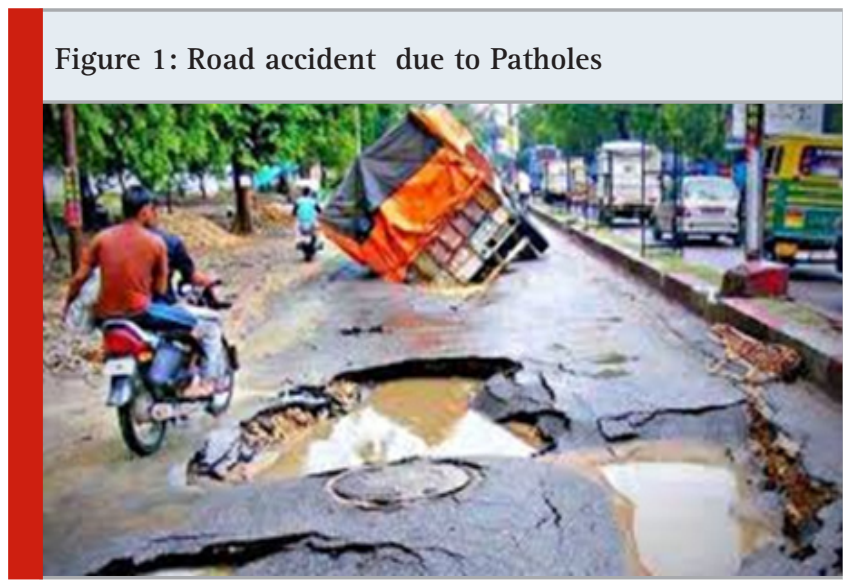

Figure 2: Raspberry Pi Board

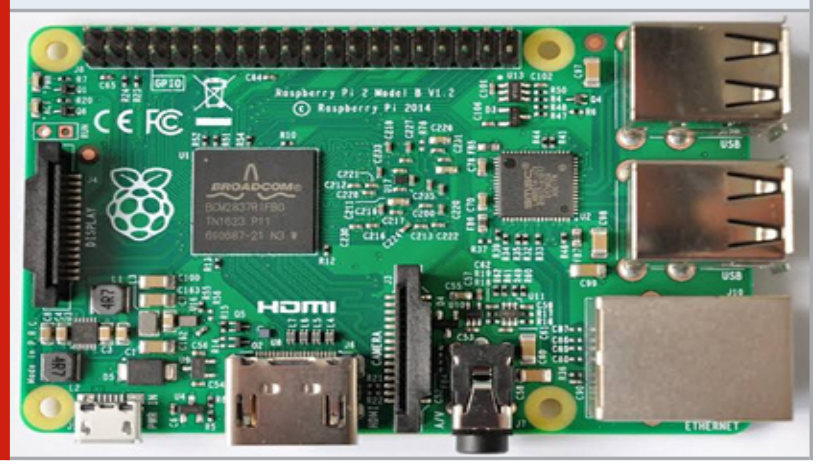

For Navigation systems, GPS Module plays the important role. An advanced real-time navigation system developed when Raspberry Pi interfaced with a GPS. The four pins present at the GPS Module are Vcc, Ground, RX and TX. The input power required is about $5 \mathrm{~V}$ voltage and $100 \mathrm{~mA}$ current. The TX pin of GPS module connected to the RX pin of Raspberry Pi. The proper grounding of the GND pin of the GPS and Raspberry Pi. Loading the program in to Raspberry Pi opened in the Python editor to receive the serial data. Note- GPS Module must be at least near to the window for perfect signal integrity.

3. Problem Definition: Major challenges are faced in the road transportation because of poor quality of roads, low maintenance, potholes and humps. Due to low maintenance and lack of information regarding damaged road, many accidents takes place. The Potholes on the road are created due to heavy rains and very fast movement of vehicles on the constructed roads. Due to Potholes accident occurs and sometimes loss of human life also. Indian speed breakers are constructed in order to control the speed of a vehicle but sometimes due to heavy rains or various factors, drivers are unable to identify humps on the road and vehicle gets unbalanced. This is the major reason for accidents. Due to the low maintenance and incorrect constructions, accidents may occur. So, all information regarding unwanted potholes and humps should be provided to the municipal corporation for the improvement of road condition. [3] [9]

The proposed intelligent system gathers the information of potholes and humps which is fitted in any vehicle for the real-time detection. It alerts the driver from road accidents and also inform about the road conditions to the higher authorities known as municipal officials through Email. The captured images are given them for the improvement of road condition which eventually helps for the economic development as well. The program to perform the detection written in python language that will be loaded to Raspberry Pi which is a series of small single board computers through USB port.[1]

Figure 3: Block Diagram of Proposed Automatic Detecetion Of Potholes And Humps

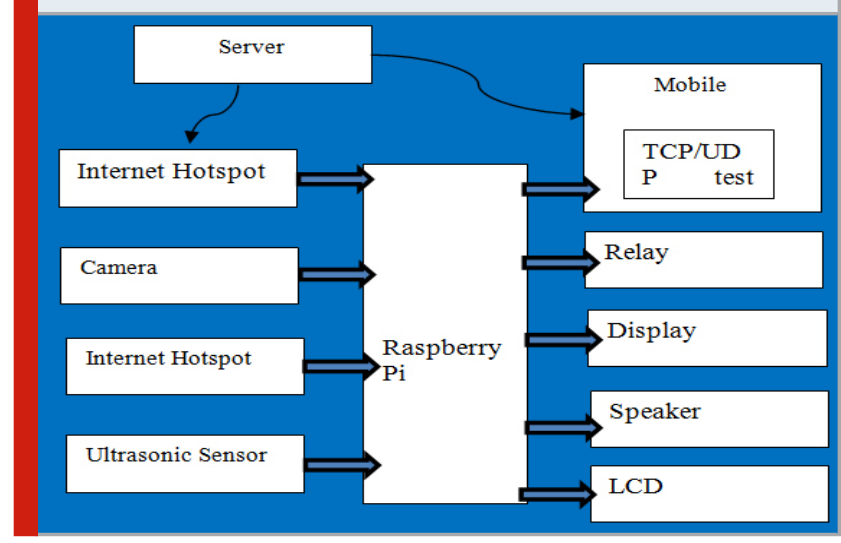

a. Potholes Detection: Wi-Fi is used for tracking location of the vehicle. The camera placed in front of the vehicle continuously captures the images of the road through the open source computer vision in a Red, Green and Blue model (i.e. RGB form.). It is difficult to visualize the RGB form of the image; therefore the image is converted into Hue Saturated Vision (HSV) form by the image processing technique. When the captured image matches with the conditions of the program, a GPS module compatible with Raspberry $\mathrm{Pi}$ is used to obtain the longitude and latitude information. The information will be provided to the NMC with the captured image. As soon as the potholes are detected, the driver is alerted via speaker acting as a alert system. Information in the form of location and the image of Potholes is saved in micro SD card for further references. The image is show to the driver through LCD display. This process is repeated at every contact of the pothole.[7] 
b. Hump Detection: Ultrasonic sensor plays a vital role for continuously measuring the distance between the vehicle and the road. The distance obtained is further compared with the set value of threshold. Each time, when the distance of a vehicle and the hump is smaller than the set threshold then it eventually alerts the driver by speaker as well as by displaying on the LCD screen. This process is carried out, every time the detection is done.[5]. The following block diagram shown in figure-3 gives the proposed automatic detection of potholes and humps

\section{CONCLUSION}

The main space of project is to go looking out the potholes. Thus, many efforts being created for the advancing a technology for automatic detection and acknowledge potholes and along contribute towards the event . The mobile application used throughout this system is an extra blessings as a results of it give timely alert concerning potholes and humps. The information inborn from here is being given to the involved street administration specialist through this application for any techniques and action on it. This answer on add time of year once potholes unit full of muddy water as alerts unit generated exploitation determination the information hold on in info. The instructed approach is economic declare detection of potholes and irregular humps as a results of it uses low value unbearable sensors .On these lines driver's security is to boot increased with foundation of location of potholes and hindrance. It would originate totally utterly completely different serves to general security and else for the advancement of the state.[8]

\section{REFERENCES}

B. G. Shivaleelavathi, Veeramma Yatnalli, Chinmayi, Yamini V. S, Spoorthi Thotad, Design and Development of an Intelligent System for Pothole and Hump Identification on Roads, International Journal of Recent Technology and Engineering,Volume-8 Issue-3, Karnataka,5294-5299,September 2019,10.35940/ijrte. C5936.098319.

Dinesh B. Bhoyar, Shelly R. Wankhede, Swati K. Modod. "Chapter 40 Design and Implementation of AES on FPGA for Security of IOT Data", Springer Science and Business Media LLC, 2020

Dinesh Bhoyar, Barkha Katey, Manish Ingale " LoRa technology based low cost water meter reading system "Esvier SSRn Information Systems and Ebusiness Neyworks ISSN 1556-5066

Kunal D. Patil, Shardul R. Patil, Vipul V. Kale, Shubham S. Thorat, Automatic Detection and Notification of Potholes and Humps on Roads, International Journal of Advance Research in Science and Engineering, Volume No. 07, Special Issue No. 03, Peth, February 2018, ISSN; 2319-8354

Madhumathy P., Saurabh Singh, Shivam Shukla, Unni Krishnan, Detection of Humps and Pothles on Roads and Notifying the same to the Drivers, International Journal of Management and Applied Sciences, Volume-3, Issue-1, Special Issue-2, Bangalore, Jan-2017, ISSN: 2394-7926

Parag Kadale, Shivam Barde, Anand Pawar, Automatic Detection of Potholes and Humps on Road, International Journal of Scientific Engineering and Research, Volume 6 Issue 5, 2347-3878,pune,May 2018, IJSER172514.

Prof. R. M. Sahu, Mayank Kher, Nurul Hasan, Laxmi Panchal, Automatic Detection of Potholes and Humps on Roads to Aid Driver, Vol-3 Issue-2, Maharashtra, IJARIIE- ISSN(0)-2395-4396

Rajeshwari Madli, Praveenraj Pattar, Santhoshs Hebbar, Automatic Detection and Notification of Potholes and Humps on Roads to Aid Drivers, IEEE Sensors Journal, VOL. 15, NO. 8, banglore,4313-4317,August 2015,10.1109/JSEN.2015.2417579.

Ruchi Bagul, Tejvi Trivedi, Rajda Vinchu, Kavita Bani, Automatic Potholes Detection and Alert System with Speed reduction feature to aid Drivers, International Research Journal of Engineering and Technology (IRJET),Volume: 07 Issue: 02, Maharashtra,1446-1449, Feb 2020,e-ISSN: 2395-0056,p-ISSN 2395-0072.

S Gayathri, Mamatha RG, Manasa B, Menita Patil, Sanjana BM, Automatic Pothole Detection System, International Journal of Engineering Research \& Technology (IJERT),Volume 7, Issue 10,mysuru,15,NCRACES - 2019 Conference Proceedings,22780181.

U. Ajitha, Sunitha Sharma, V. Arumuga Selvi, Aswini Priyanka, Smart Sensing of Potholes and Obstacles in Automotive Applications, International Journal of Pure and Applied Mathematics, Volume 119, No. 15, Chennai, 2018, 1479-1486, ISSN: 1314-3395. 